\title{
A decision support model to incorporate public and expert opinions for assessing the privatization of public bus transit system: Application of ELECTRE for the bus system in Eskisehir, Turkey
}

\author{
Nadir Yayla ${ }^{1}$ and Murat Karacasu ${ }^{2 \star}$ \\ ${ }^{1}$ Department of Civil Engineering, Istanbul Technical University, Istanbul, Turkey. \\ ${ }^{2}$ Department of Civil Engineering, Eskisehir Osmangazi University, Eskisehir, Turkey.
}

Accepted 17 August, 2011

\begin{abstract}
This paper proposes a multicriteria model for assessing public bus operation systems based on the ELECTRE method in the city of Eskisehir, Turkey. In this specific problem, public and expert opinions towards the privatization of urban bus lines were collected through a comprehensive survey to determine the best operation system; either by the local authority or private operators. The data collected include the opinions of four different groups of people namely: system users, transportation administrators, civil organizations and experts in the transportation field. The ELECTRE model yielded that the privatization of the bus system is preferred (by 37 to 14 points) over its operation by the public entity (local municipality).
\end{abstract}

Key words: Decision support system, public bus operation, Electre method, public participation.

\section{INTRODUCTION}

Many transportation projects involve great public resources and in turn their critical values and choices need to be reflected in the process of project selection among viable alternatives. Therefore, several countries have realized the importance of getting public participated in transportation planning and formal decision making process. Such as the Transportation Equity Act (TEA-21) of the USA formally requires public involvement in transportation planning from all state Departments of Transportation and the White Paper of the UK requires local authorities to undertake extensive consultation with the public and other stakeholders (DETR, 1998). The purpose of a public involvement process (PIP) is to not only on informing the public about what is going to happen but also in actively seeking their input in the process of large public investments. A PIP

*Corresponding author. E-mail: muratk@ogu.edu.tr. Tel: +90222-2393750x3211. Fax: +90-222-2393613. aims to solicit and consider the public opinion in forming transportation policy (Podgorski and Kockelman, 2005). Despite the support provided for this initiation from the governments in those countries, through the eyes of public, particularly low income and minority community residents, this process is often viewed suspiciously and not designed to address community based concerns and issues (Robinson, 2007). Furthermore, there still needs for defining a general framework for the collaborative public participation activities. Due to conflicting interests of the participating public, for example beneficiaries and bearers of costs vary with respect to criteria considered, such a decision making process can be more complex that coupled with a high degree of uncertainty adds on to this conflict (Gamper and Turcanu, 2007). Contextual variations across the participating public and criteria influencing the decision let the adoption of a multi-criteria analysis (MCA) be evident. Although MCA is an important tool for public decision making, the legal requirement for its use is seldom. Among those, the project selection for public works in the Italian law (www.legge109-94.it/leges/ 
DPR\%20554-1999.doc), decision making process for acquisitions of data-processing equipment, consulting services and such in Spain (Barba-Romero, 2001) and public decision making for water resource planning, forestry and agriculture in the USA law (Joubert et al., 1997).

The use of MCA has recently also increased in the public domain such as in public transportation systems (Bana e Costa and Nunes da Silva, 2001; Larsson, 2001; Mousseau, 2001). A good review about the legal requirements for MCA is provided by several researchers (Bana e Costa and Nunes da Silva, 2001; Larsson, 2001; Mousseau, 2001). There are also a variety of methods in literature for transportation project selection process; different approaches have been developed for this purpose. In general, these approaches can be aligned into five categories: 1) profile and checklist method, 2) scoring methods, 3) cost-benefit analysis (CBA), 4) mathematical programming models, 5) fuzzy reasoning (Avineri et al., 2000; Arslan, 2009) and 6) composite or hybrid models. Except the profile and checklist method where alternatives are ranked according to a given set of criteria and results are visually displayed in a way that allows easy comparison, the others are all analytical instruments having different underlying methodologies and provide a decision-making framework from problem definition to valuation of decision alternatives and as a result to comparing/ranking alternatives. Not all methods are adequate to solve a specific problem; therefore a method can be inappropriate for a particular case (Gilliams et al., 2005). Therefore, an addition to aforementioned methods, in this study, the ELECTRE model is used as a new method in this field.

\section{Decision making process}

In a decision making process with public involvement, preferences should be revealed, and the process should allow policy makers to be more focused on critical factors. A subjective evaluation itself may not provide a profitable transport policy; however, having public participate in transportation project selection can offer a higher probability of selecting a solution that meets the multiple demands of relevant stakeholders considering scarce public resources. In this sense, public opinions should form a foundation for determining the projects' strengths and weaknesses. Then, policy makers can be more aware of public concerns before implementing high cost transportation projects. This can further provide an opportunity to make necessary changes to obtain necessary public support. As transportation planning involves public resources and values, judgments by the citizens should play leading roles in determining final decisions. This is also of importance for realizing support and advocacy for implementing transportation projects from policy makers' point of view. Decision support methods for such decision making cases should reflect subjective natures of public's opinions. The picture is, however, is not good in that sense in Turkey. Although, this issue of public involvement in large transportation projects has been highlighted in the Eight Five-year Development plan (http://ekutup.dpt.gov.tr/plan/viii/plan8str.pdf), there has been no apparent application seen in reality using a PIP. In this paper, the ELECTRE (the elimination and choice translating reality) method proposed by Roy (1991) was used to examine the results of a public survey conducted to seek the public approval for two different types of a public bus operation system in the city of Eskisehir, Turkey; the one run by the municipal authority and the other run by private sector.

The ELECTRE method is facilitated to reveal the preferences by obtaining the complete ordering between the two public bus operating systems. Important findings are outlined based on the results. The remainder of this study is structured as follows: subsequently, it provides the materials used and methods applied; then it gives a numeric application of the method. Lastly, conclusions and suggestions are discussed.

\section{THE FRAMEWORK AND DATA}

The public transportation in Turkey is generally provided by local authorities. Due to a high number of low income people as well as young population, public dependence on the public transportation system is extremely vital in Turkey. However, most of the cases services provided by local authorities remain insufficient to provide comfortable and reliable public transportation services due to logistically awkward infrastructures. Bus is the main mean for the public transportation services in many cities. Although, the participation of stakeholders and real and effective consultation are more essential in the case of self regulation of public transportation service than in other regulatory regimes (Sohail and Maunder, 2006), there has been no application in action yet except some voting on the type and color of the buses in many cities. However, as it has been experienced recently, it can cause irrational decisions on public transportation systems that can bring huge burden on the budget of local authorities (http://www.milliyet.com.tr/, 2009).

\section{The data}

In Eskisehir, a rapidly growing city of Turkey, a survey was conducted to determine a better bus operating system between the two alternative choices; namely: the one run by the local authority and the other run by private operators. The data were collected from four groups of subjects classified as general public, transportation administrations at city as well as national level, civil 


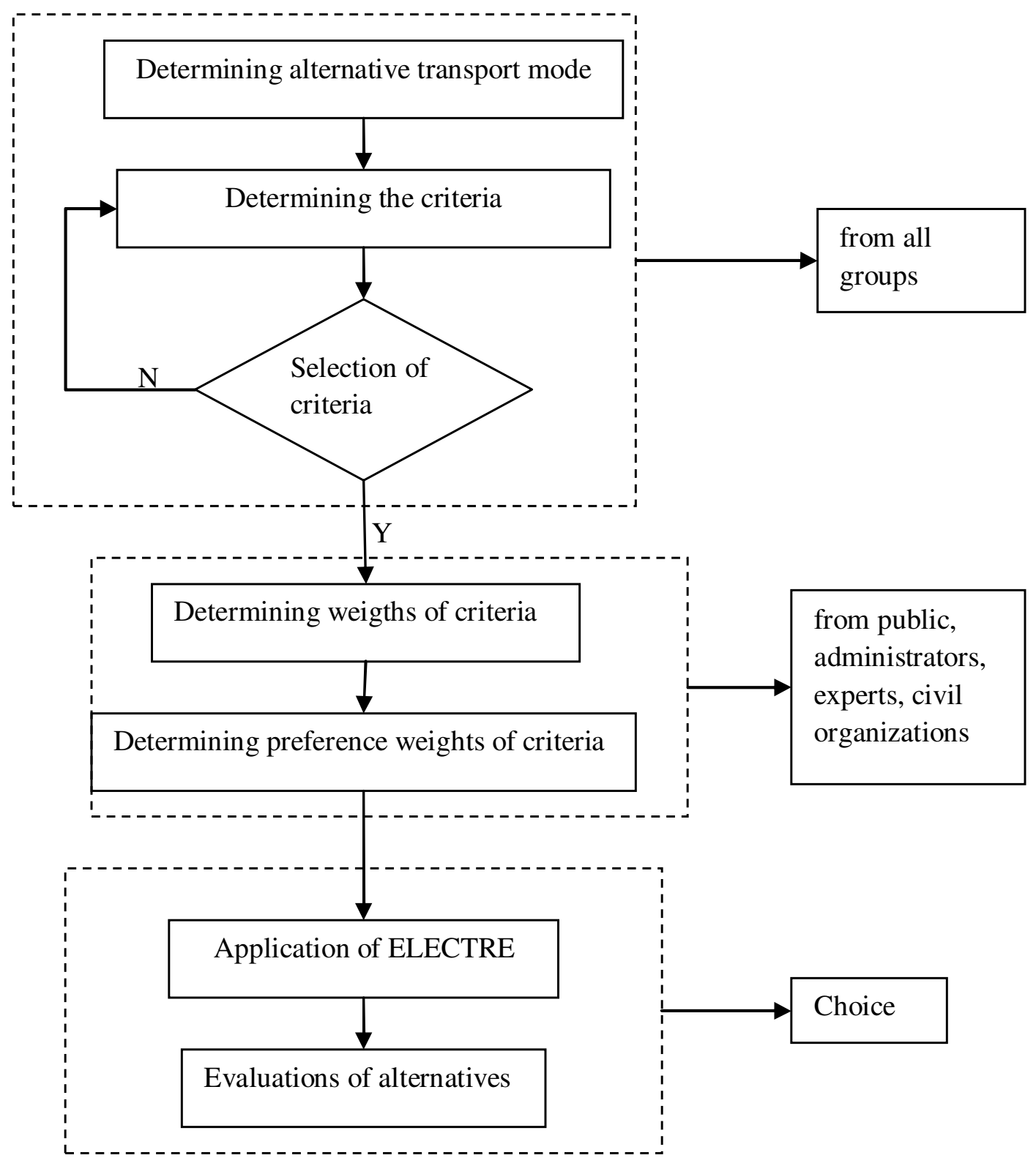

Figure 1. The structure of suggested decision support model.

organizations and transportation experts. Except for the city transportation administration group, the others represent different sectors of the public domain. The participants of the general public stakeholder were the randomly selected residents of the city Eskisehir. The people participating in the civil organizations group were people who work for and represent several civil organizations such as the Environmental Protection Organization, Turkish Handicap Association and so on. The people in the expert group were, on the other hand, academicians from several national universities and experts in the field from several consulting companies and transportation departments at local as well as national level. The structure of the suggested decision support model is shown in Figure 1. A total of 689 people participated in the public group. Based on face-to-face interviews, 547 of them provided their opinions during interviews in their homes and the other 142 were interviewed in several bus stations in Eskisehir. The transportation administration group consisted of nine people, while eight persons took part in the civil organization group. A total of 52 experts participated in the survey. In the first part of the survey, except for the expert group, all subjects defined the criteria that can be 
Table 1. Criteria for each group.

\begin{tabular}{|c|c|c|c|c|}
\hline \multicolumn{5}{|c|}{ Criteria $\left(p_{j}\right)$ and $n=$ the number of criteria } \\
\hline Symbol & Public $(n=14)$ & Transportation administration $(n=13)$ & Civil organizations $(n=6)$ & Experts $(n=33)$ \\
\hline $\mathrm{p}_{1}$ & Fare & Fuel cost & Effects in car usage & \multirow{14}{*}{ All criteria $(14+13+6)$} \\
\hline $\mathrm{p}_{2}$ & Comfort of service & Maintenance cost & Effects in quality of life & \\
\hline $\mathrm{p}_{3}$ & Vehicle cleanliness & Personal cost & Public satisfaction & \\
\hline $\mathrm{p}_{4}$ & Payment type & Amortization & Environmental effects & \\
\hline $\mathrm{p}_{5}$ & Fullness & Accident cost & Service quality for disabled people & \\
\hline $\mathrm{p}_{6}$ & Possibility of travelling seated & Insurance cost & Economical benefit from privatization & \\
\hline $\mathrm{p}_{7}$ & Staff attitude & Profit & & \\
\hline $\mathrm{p}_{8}$ & Standards of vehicles & Productivity & & \\
\hline $\mathrm{p}_{9}$ & Bus station conditions & Flexibility in decision & & \\
\hline $\mathrm{p}_{10}$ & Service reliability & Future investments & & \\
\hline $\mathrm{p}_{11}$ & Time reliability & Standards of vehicles & & \\
\hline $\mathrm{p}_{12}$ & Service frequency & Possibility in renewing fleet & & \\
\hline$p_{13}$ & Travelling time & Safe from accidents & & \\
\hline$p_{14}$ & Safe from accidents & & & \\
\hline
\end{tabular}

important for their own groups. Then, subjects in each group used a 5-point scale to rate their opinions on those criteria important for their own group. Total criteria defined by each group are given in Table 1.

The data collected from the experts are used in this paper for the ease of computation along with the data suitability. For the same reason, among the 33 criteria, only 6 important attributes are selected for avoiding the problem of dimensionality. The selected criteria are comfort of service (CS), payment type (PT), service reliability (SR), time reliability (TR), flexibility in decision (FD) and standards of vehicles (SV).
These simplifications, however, do not affect the validity of the methods.

\section{The method of ELECTRE}

Transportation investment decision problems are of important and have significant impacts on the sustainable developments. However, many problems encountered in transportation planning are highly complex and mostly none-linear in nature. Several criteria are considered and evaluated in terms of many different conflicting criteria in such decision making cases. Traditional methods such as scoring, checklist and cost-benefit analysis (CBA) are not adequate to capture subjective opinions. As an alternative, the ELECTRE method is used to evaluate public bus operating alternatives as a case problem in this study. The ELECTRE (the elimination and choice translating reality) method proposed by Roy (1991) has the capability of handling discrete quantitative and qualitative criteria in nature and provides complete ordering of the alternatives. The method accommodates the imprecision and uncertainty in a way similar to human decision making process on the use of indifference, preference and veto (Natividade-Jesus and Coutinho-Rodrigues, 2007). Relying upon the concordance (a majority of criteria support) and non-discordance (no criterion is strongly opposed to) principles, it defines that: "alternative A outranks alternative B" meaning that: "A is at least as good as B".

Moreover, weights do not depend on the nature of the criterion scales; therefore they possess the true meaning of relative importance given to the distinct criteria (NatividadeJesus and Coutinho-Rodrigues, 2007). The ELECTRE 
method is explained according to Hwang and Yoon (1981) work in steps as follows:

1) The procedure of the method starts with defining decision matrix, $\mathrm{P}$, which represents the preference weights of alternatives with respect to each criterion:

$\mathbf{P}=\left[\begin{array}{ccc}p_{11} & \cdots & p_{1 n} \\ \vdots & \ddots & \vdots \\ p_{m n} & \cdots & p_{m n}\end{array}\right]$

Where $m$ is the number of alternatives and $n$ is the number of criteria considered.

2) Then, the weight matrix, $W$, is defined, which is directly taken from survey:

$\mathbf{W}=\left[\begin{array}{ccc}w_{1} & \cdots & 0 \\ \vdots & \ddots & \vdots \\ 0 & \cdots & w_{n}\end{array}\right]$

3) The ' $K$ ' matrix is formed by normalizing the elements of the ' $P$ ' matrix into coefficients as:

$$
k_{i j}=\frac{p_{i j}}{\sqrt{\sum_{i=1}^{m} p_{i j}^{2}}}
$$

4) The weighted normalized decision matrix, 'N', can be found as follows:

$$
\mathbf{N}=\mathbf{K W}
$$

5) The concordance matrix, ' $C$ ', is formed by using the concordance set. For each pair of alternatives $k$ and $l(k, l=1, \ldots, m$ and $k \neq l$ ), the set of decision criteria $J=\{j \mid j=1,2, \ldots, n\}$ is divided into two distinct subsets. The concordance matrix 'C' of $A_{k}$ and $A_{l}$ is composed of all criteria for which $A_{k}$ is preferred to $A_{l}$. In other words:

$c_{k l}=\left\{j \mid p_{k j} \geq p_{l j}\right\}$

The relative value of the concordance set is measured by means of the concordance index. The concordance index is equal to the sum of the weights associated with those criteria which are contained in the concordance set. Therefore, the concordance index $c_{k l}$ between $A_{k}$ and $A_{l}$ is defined as:

$c_{k l}=\sum_{j \in C_{k l}} w_{j}$
The concordance index reflects the relative importance of $A_{k}$ with respect to $A_{l}$. Obviously, $0 \leq c_{k l} \leq 1$. A higher value of $c_{k l}$ indicates that $A_{k}$ is preferred to $A_{l}$ as far as the concordance criteria are concerned. The successive values of the concordance indices $c_{k l}(k, l=1, \ldots, m$ and $k \neq l)$ form the concordance matrix 'C' of $(m \times m)$ :

$\mathbf{C}=\left[\begin{array}{cccc}- & c_{12} & \cdots & c_{1 m} \\ c_{12} & - & c_{23} & c_{2 m} \\ \vdots & \ldots & \cdots & \vdots \\ c_{m 1} & c_{m 2} & c_{m(m-1)} & -\end{array}\right]$

6) On the other hand, the disconcordance matrix, 'D', which is the complementary matrix of concordance matrix is formed as:

$d_{k l}=\left\{j \mid p_{k j}<p_{l j}\right\}=J-c_{k l}$

The concordance index reflects the relative dominance of a certain alternative over a competing alternative on the basis of the relative weight attached to the successive decision criteria. In order to determine the degree to which $A_{k}$ is worse than $A_{l}$, another index is defined as:

$d_{k l}=\frac{\max _{j \in D_{k l}}\left|n_{k j}-n_{l j}\right|}{\max _{j \in J}\left|n_{k j}-n_{l j}\right|}$

It is seen that $0 \leq d_{k l} \leq 1$. A higher value of $d_{k l}$ implies that $A_{k}$ is less favorable than $A_{l}$ and a lower value of $d_{k l}$, on the other hand, it implies the opposite. The discordance indices form the discordance matrix ' $\mathrm{D}$ ' of $(m \times m)$ :

$\mathbf{D}=\left[\begin{array}{cccc}- & d_{12} & \cdots & d_{1 m} \\ d_{12} & - & d_{23} & d_{2 m} \\ \vdots & \ldots & \cdots & \vdots \\ d_{m 1} & d_{m 2} & d_{m(m-1)} & -\end{array}\right]$

7) The concordance dominance matrix is calculated with the aid of threshold value for the concordance index which indicates $A_{k}$ 's chance of dominating $A_{l}$. The threshold value can be determined, for example, as the average concordance index:

$$
r=\sum_{\substack{k=1 \\ k \neq l}}^{m} \sum_{\substack{l=1 \\ l \neq k}}^{m} \frac{c_{k l}}{m(m-1)}
$$

On the basis of $r$ threshold value, 'F' matrix can be constructed, the 
Table 2. Concordance set (C).

\begin{tabular}{lccccccc}
\hline & & & & & & & $\boldsymbol{\Sigma}$ \\
\hline $\mathrm{c} 12$ & 0 & 0 & 0 & 0 & 0 & 0 & 0 \\
$\mathrm{c} 21$ & 0.18 & 0.15 & 0 & 0.18 & 0 & 0.18 & 0.68 \\
\hline
\end{tabular}

elements of which are defined as:

$$
f_{k l}=\left\{\begin{array}{l}
1, \text { if } c_{k l} \geq r \\
0, \text { if } c_{k l}<r
\end{array}\right\}
$$

An alternative's dominance over another one is numerically indicated as 1 in the ' $F$ ' matrix.

8) In a similar fashion, the discordance dominance matrix is constructed and based on the threshold value, the elements of $g_{k l}$ of the discordance dominance matrix ' $G$ ' are calculated as:

$$
z=\sum_{\substack{k=1 \\ k \neq l}}^{m} \sum_{\substack{l=1 \\ l \neq k}}^{m} \frac{d_{k l}}{m(m-1)}
$$

and

$$
g_{k l}=\left\{\begin{array}{l}
1, \text { if } d_{k l} \leq z \\
0, \text { if } d_{k l}>z
\end{array}\right\}
$$

9) Finally, the ' $T$ ' aggregate dominance matrix is found by calculating the intersection of the concordance dominance matrix ' $F$ ' and discordance dominance matrix ' $G$ '. ' $T$ ' is defined by means of its typical elements $t_{k l}$ as:

$$
t_{k l}=f_{k l} \times g_{k l}
$$

The aggregate dominance matrix, ' $T$ ', gives the partial preference ordering of the alternatives. If $t_{k l}$ element of $\mathbf{T}_{k l}$ matrix equals to 1, then alternative $A_{k}$ is preferred to alternative $A_{l}$. In this case, alternative $A_{l}$ is eliminated.

\section{The numeric application}

Using the simplified data as explained in this study, a numerical application of the ELECTRE method is exemplified in here. The alternative A1 indicates the public bus system owned and operated by the municipality and the alternative A2 represents the system operated by one or several private agencies (public regulation of bus operating lines, operation hours, fares, and the service ownership by the municipality are still effective), respectively. The numerical example is shown on a subject's input that he/she was provided, accordingly:

Decision matrix, 'P', and weight matrix, 'W', are obtained from the survey as follows:

$$
\mathbf{P}=A 1\left[\begin{array}{cccccc}
C S & P T & S R & T R & F D & S V \\
0.40 & 0.45 & 0.55 & 0.45 & 0.55 & 0.45 \\
0.70 & 0.60 & 0.55 & 0.75 & 0.55 & 0.80
\end{array}\right]
$$

$\mathbf{W}=\left[\begin{array}{cccccc}C S & P T & S R & T R & F D & S V \\ 0.18 & 0.15 & 0.16 & 0.18 & 0.16 & 0.18\end{array}\right]$

1) Columns of ' $P$ ' matrix are normalized by dividing each element in the column by the square roots of the sum of squares of the elements in the column. The resulting normalized decision matrix, ' $\mathrm{K}$ ', is calculated as:

$$
\mathbf{K}=A 1\left[\begin{array}{cccccc}
C S & P T & S R & T R & F D & S V \\
0.50 & 0.60 & 0.71 & 0.51 & 0.71 & 0.49 \\
0.87 & 0.80 & 0.71 & 0.86 & 0.71 & 0.87
\end{array}\right]
$$

2) Next, the weighted normalized decision matrix, ' $\mathrm{N}$ ', can be obtained from Equation 4, multiplication of matrices ' $\mathrm{K}$ ' with 'W':

$$
\mathbf{N}=A 1\left[\begin{array}{cccccc}
C S & P T & S R & T R & F D & S V \\
0.09 & 0.09 & 0.11 & 0.09 & 0.11 & 0.09 \\
0.15 & 0.12 & 0.11 & 0.15 & 0.11 & 0.15
\end{array}\right]
$$

3) Then, the concordance matrix is constructed by comparing values of the alternatives from the last matrix: whichever is bigger, when compared, the corresponding criterion's normalized weight from the ' $W$ ' matrix is taken in, otherwise zero is taken in. The sum of each row presents the concordance matrix elements of off diagonal elements. It should be noticed that the diagonal elements are all zeros. The corresponding concordance set for this particular example is given in Table 2 .

4) Accordingly, the ' $C$ ' matrix is: 
Table 3. Absolute values for criteria.

\begin{tabular}{cccccccc}
\hline & CS & PT & SR & TR & FD & SV & Max \\
\hline$\left|n_{k j}-n_{l j}\right|$ & 0.07 & 0.03 & 0.00 & 0.06 & 0.00 & 0.07 & 0.07 \\
\hline
\end{tabular}

Table 4. Disconcordance set (D).

\begin{tabular}{llllllll}
\hline & & & & & & & Max \\
\hline $\mathrm{d} 12$ & 0.07 & 0.03 & 0.00 & 0.06 & 0.00 & 0.07 & 0.07 \\
$\mathrm{~d} 21$ & 0.00 & 0.00 & 0.00 & 0.00 & 0.00 & 0.00 & 0.00 \\
\hline
\end{tabular}

$$
\mathbf{C}=A 1\left[\begin{array}{cc}
A 1 & A 2 \\
0 & 0 \\
0.68 & 0
\end{array}\right]
$$

5) According to the ' $C$ ' matrix, the average concordance index can be obtained from Equation 11 as:

$r=\frac{0+0.68}{2}=0.34$ and,

6) ' $F$ ' concordance dominance matrix can be constructed from Equation 12 as:

$c_{12}=0<0.34$ in that case $f_{12}=0$ and;

$c_{21}=0.68>0.34$ in that case $f_{21}=1$

$$
\mathbf{F}=A 1\left[\begin{array}{cc}
A 1 & A 2 \\
0 & 0 \\
1 & 0
\end{array}\right]
$$

7) On the other hand, as the complementary matrix of the concordance matrix, the discordance matrix is found by replacing the zeros in concordance matrix elements with corresponding elements from the previous matrix from Equation 8, if both elements are not equal to zero. The maximum of each row represents the disconcordance matrix elements of off diagonal elements which are all zeros.

8) According to matrix ' $N$ ' absolute values can be obtained from Equation 9. Then maximum value of these is found as given in Table 3.

9) Then, disconcordance set can be obtained from
Equation 9 as Table 4:

10) Accordingly, the 'D matrix is:

$$
\mathbf{D}=A 1\left[\begin{array}{cc}
A 1 & A 2 \\
0 & 1 \\
0 & 0
\end{array}\right]
$$

11) According to ' $D$ ' matrix, average disconcordance index can be obtained from Equation 13 as:

$z=\frac{0+1}{2}=0.50$ and

12) $G$ disconcordance dominance matrix can be calculated from Equation 14 as:

$d_{12}=1>0.50$ in that case $g_{12}=0$ and;

$d_{21}=0<0.50$ in that case $g_{21}=1$

$$
\mathbf{G}=A 1\left[\begin{array}{cc}
A 1 & A 2 \\
0 & 0 \\
1 & 0
\end{array}\right]
$$

13) Finally, the ' $T$ ' aggregate dominance matrix can be found from Equation 15.

$$
\mathbf{T}=A 1\left[\begin{array}{cc}
A 1 & A 2 \\
0 & 0 \\
1 & 0
\end{array}\right]
$$

According to ' $T$ ' matrix, 1 (one) in a row indicates its 
Table 5. The model results.

\begin{tabular}{lc}
\hline Parameter & Results \\
\hline Publicly owned and operated (A1) & 14 \\
Privately operated (A2) & 37 \\
Undecided & 1 \\
\hline
\end{tabular}

dominance over the other alternative represented by the column. As here, the privatization of the bus system is preferred over its operation by the public entity. The overall result considering all the data is presented in Table 5. It is seen that most of the subjects has preferred the bus system operated by private agencies over the public bus system operated by the municipal entity.

\section{Conclusion}

This paper proposed the ELECTRE method as a multicriteria model for assessing public bus operation systems in the city of Eskisehir, Turkey. Public and expert opinions towards the privatization of urban bus lines were collected through a comprehensive survey to determine the best operation system; either by the local authority or private operators. The data collected include the opinions of four different groups of stakeholders: 1) system users, 2) transportation administrators at local as well as national level, 3) civil organizations, and 4) the experts in the transportation field. The ELECTRE model yielded that the privatization of the bus system is preferred (by 37 to 14 points) over its operation by the public entity (local municipality). The ELECTRE model was able to well respond under several conflicting criteria. The only weakness was that the model provided the final selection as either one or zero, selected or not selected. That could obscure the overall preference tendency which may be useful in further process of the projects from the policy makers' point of view. However, using the results presented in Table 5, that weakness is no longer effective.

\section{REFERENCES}

Arslan T (2009). A hybrid model of fuzzy and AHP for handling public assessments on transportation projects. Transportation, 36(1): 97112.
Avineri E, Prashker J, Ceder A (2000). Transportation Projects Selection Process using Fuzzy Sets Theory. Fuzzy Sets and Systems, 116: 35-47.

Bana e Costa CA, Nunes da Silva F (2001). Conflict dissolution in the public sector: A case-study. Eur. J. Operat. Res., 130(2): 388-401.

Barba-Romero S (2001). The Spanish Government Uses a Discrete Multicriteria DSS to Determine Data-Processing Acquisitions. Interfaces, 31(4): 123-131.

DETR (1998). A New Deal for Transport: Better for Everyone, HMSO, London.

Gamper CD, Turcanu C (2007). On the governmental use of multicriteria analysis. Ecol. Econ., 62(2): 298-307.

Gilliams S, Raymaekers D, Muys B, Orshoven JV (2005). Comparing multiple criteria decision methods to extend a geographical information system on afforestation. Comput. Elect. Agric., 49(1): 142-158.

Hwang CL, Yoon K (1981). Lecture Notes in Economics and Mathematical Systems, Multiple Attribute Decision Making Methods and Applications. New York: Springer-Verlag.

Joubert AR, Klerk HM, Katua S, Aggenbach JC (1997). Fynbos (fine bush) vegetation and the supply of water: a comparison of multicriteria decision analysis and cost-benefit analysis. Ecol. Econ., 22: 123-140.

Larsson SO (2001). Multi-criteria decision support in a road-planning process - a Swedish case. A-MCDA-A Aide Multi Critère à la Decision-Multiple Criteria Decision Aiding, Office for Official Publications of the European Communities, Luxembourg, pp. 163170.

Milliyet, Turkish Daily Newspaper. Kentiçine Uygun Değil Raporu (A Report, not Proper for Use in City Streets). 12 May 2009. (http://www.milliyet.com.tr/

Yasam/HaberDetay. aspx?aType=HaberDetay\&KategorilD=5\&Articlel $\mathrm{D}=1093635 \& \mathrm{Date}=12.05 .2009 \& \mathrm{~b}=$ Kent\%20icine\%20uygun\%20degil $\% 20$ raporu).

Mousseau BR (2001). Development of a decision aiding tool for the evolution of public transport ticket pricing in the Paris region. AMCDA-A Aide Multi Critère à la Decision-Multiple Criteria Decision Aiding, Office for Official Publications of the European Communities, Luxembourg, pp. 297-314.

Natividade-Jesus E, Coutinho-Rodrigues J (2007). A multicriteria decision support system for housing evaluation. Decision Support Systems, 43(3): 779-790.

Podgorski KV, Kockelman KM (2005). Public Perceptions of Toll Roads: A Survey of the Texas Perspective. Transportation Research Board 86th Annual Meeting, CD-ROM, National Research Council, Washington, D.C.

Robinson G (2007). Environmental Justice in Transportation Toolkit.

www.fta.dot.gov/documents/TECRP_Task_I-3B_Final.doc.

Roy B (1991). The outranking approach and the foundations of electre methods. Theory and Decision, 31(1): 49-73.

Sohail M, Maunder DAC (2006). Effective regulation for sustainable public transport in developing countries. Transport Policy, 13(3): 177190. 